by the operation of testis-grafting is possibly justified, but the evidence presented has not been based upon critical experimentation. The delegates were not satisfied that this method, even if and when its merits have been fully demonstrated, can become of any great importance in a country such as. Great Britain. The claim of Dr. Voronoff to increase the body weight and the wool-clip of the ram by the operation of testis-grafting applied to immature male, was supported by the data submitted and by the appearance of the sheep that were seen, but the conditions under which the experiments had been conducted, the inadequacy of the data submitted, and the method of the presentation of these data, made the forming of a critical opinion quite impossible. For the same reason, it was impossible to accept the evidence, which seemed to show that the improvements thus invoked were transmitted by the ordinary processes of reproduction. There is great need for repetition of these experiments with standardised material under controlled conditions of husbandry.

\section{Sir David Ferrier, F.R.S.}

$\mathrm{T}^{\mathrm{H}}$ HE death of Sir David Ferrier in London on Mar. 19 removes from the roll of living neurologists a veteran pioneer, eminent in example and in service. He had reached his eighty-sixth year, and his life meant for those at work to-day a personal tie with a historic past which he conspicuously had helped to make significant.

Ferrier, as student in Aberdeen, his native city, had been a pupil of mark under the psychologist and philosopher Alexander Bain, and had graduated at the University with high honours. He had then entered upon medicine at the University of Edinburgh. The study of the nervous system attracted him early; and a gold medal was awarded to his M.D. thesis, "On the Corpora Quadrigemina." Later, in the reports of the West Riding Lunatic Asylum, where a centre of neurological research had arisen under Dr. (now Sir James) Crichton-Browne, Ferrier issued his first paper of experiments on the brain of some of the higher mammals. HughlingsJackson's observations upon localised discharging fits were being discussed in 1868; the famous "Study of Convulsions" followed from him in 1869. The experiments of Ferrier had for an object the "testing of the theory of HughlingsJackson that localised and unilateral epilepsies are caused by irritative or "discharging' lesions of the grey matter of the hemispheres."

Ferrier's extension of these experiments to types of brain nearer the human was encouraged by the Royal Society with a grant in aid supplying the material for the work. Ferrier was able to establish that in the ape's brain, a considerable area of the surface sheet is excitable by faradism. Localised movements in the face and limbs, of the crossed side, were evoked with such definition and precision that "the experimenter can predict with certainty the result of stimulation of a given region." Ferrier described a "motor region" stretching across the lateral aspect and thence over and upon the median aspect of the hemisphere. He pointed out that its extent was greater and its character more detailed in the ape than in any of the types less near to man. He then turned to determine the effects of localised destruction of portions of the cerebral surface. These experiments formed the main theme of a second Croonian Lecture following his earlier of 1874 . He directed attention to the hemiplegic symptoms ensuent on injury of the motor region in the ape, symptoms in several

\section{tuary.}

respects indistinguishable from human symptoms familiar in the clinic. It is related by Sir Charles Ballance that at the International Congress of Medicine in London in 1881, on the appearance of one of the monkeys shown by Ferrier, Charcot of Paris, the physician, exclaimed, "It is a patient !"

Outside and beyond the region of cerebral sur. face which he termed 'motor,' Ferrier described further certain other regions which conversely he termed 'sensory.' He distinguished separate sensory fields severally related to the several special senses. Individual destruction of these entailed, he concluded, specific sensory defects and disturbances. His lectures upon all this work were followed in 1876 by a memorable volume, "The Functions of the Brain." The book reached beyond medical circles to a wide scientific public. It was translated into various languages. It and the work it embodied exerted decisive influence toward placing cerebral localisation in the forefront of movement in the physiology and medicine, and indeed in some respects in the psychology, of its time.

If we would seek to trace the origins of Ferrier's inquiry and the great and lasting effect it produced, we must pay regard to some contemporary circumstances. Current scientific opinion, both physiological and medical, had held that the cerebrum - organ of mind' and mind a unityrevealed in its functioning no spatial differences. Further, current teaching had been that the cerebrum, unlike the spinal cord, remained in all appearance irresponsive to such stimuli, electrical and what not, as physiological experiment had resort to. There had, however, arisen recently the views of Hughlings-Jackson, based on clinical observation of epileptoid convulsions. Contrary to orthodoxy of the time, he taught the existence of motor centres situated in the grey matter of certain of the cerebral convolutions, namely, "the convolutions surrounding the corpus striatum." This teaching Ferrier's paper mentions as an impetus to, and its testing as an immediate object of, his first experiments. Ferrier's inquiry was also made in the light of observations obtained by Fritsch and Hitzig three years before, on the brain of the dog, with closing and opening of a galvanic current as stimulus. On that mode of stimulation the method adopted by Ferrier constituted an important advance. It enabled deliberate and sustained movement to be evoked and without

No. 3053, VoL. 121] 
damage to the cerebral tissue ; it allowed elicitation and study of the 'march' (that is, the spreading) of movement which Jackson had noted to be of diagnostic value in the epileptoid convulsion; it brought the clonus characteristic of epilepsy under observation as a feature of cerebral 'after-discharge.' Ferrier's method of stimulation has been followed by all observers since.

A conception which Ferrier formed regarding the localisation of function in the cortex held it to be primarily 'sensori-motor.' He conceived this region which yielded, in such systematic order, purpose-like actions of limb, etc., to represent so to say a motor executive; and he distinguished outside it, in contradistinction to it, fields which he regarded as sensory inasmuch as he read them to be dominantly connected each with a special sense. In short, ' motor' and 'sensory' were the fundamental categories underlying the scheme of localisation in the cerebral cortex in his pioneer interpretation of it. Not 'motor' and 'sensory' of course with the crudity of the efferent and afferent sides of a simple reflex arc ; but yet distinguishably ' motor ' and ' sensory.' The problem thus entered upon has exhibited during the succeeding fifty years continual increase of complexity at every renewal of attack. None the less, in intrinsic conformity with Ferrier's original point of view regarding the 'motor region,' we have to-day the experience of so versed and highly qualified an observer as Dr. Gordon Holmes, to the effect that " the precentral gyrus [the motor region proper] has no sensory functions." In addition, Ferrier's scheme, which assigned the major part of the cerebral surface to specific sensory fields, can stand as a prototype of that which comparative anatomy and cytoarchitecture have step by step since then substantiated. Also, the modern finding of Pavloff and his school arrives no less at a functional scheme which, even more than did Ferrier's original, allocates the cerebral surface to territories representing the several specific receptor-systems, with exclusion and negation altogether of " pure association' fields.

The interpretation of observations regarding cortical functions forms an arena which has seemed to invite conflict. Ferrier arrived at a conception with the fundamental simplicity of which there corresponds, very probably, a fundamental truth. As regards animal mind, analytic psychology has not yet reached the elements needed in application to the problem. Be that as it may, a tribute which was quickly paid to Ferrier's work was that subsequent investigation of the nervous system, whether by adherents or by opponents of his views, for many years did little else than search for 'localisation' of something. A tide of localisation flowed with subversion of other interests. A 'localisation' era followed on Ferrier's work. The vogue became, as time went by, tedious, and in many respects infertile; but the importance of the work which ushered it in can never be forgotten.

It is difficult now to think back to a functional neurology which resigned itself to picturing the cerebral cortex as an uncharted sea, an unknown uniformity. With Ferrier's experiments that state of things came to its term. There followed consequences theoretical and practical. One beneficent practical result was that the symptoms of certain brain tumours, etc., viewed in the light of his 'localisations' in the ape, allowed the physician to locate the seat of mischief within the skull and so sometimes enabled relief of the patient by surgery. An element of irony attaches to the fact that as a consequence of his experiments Ferrier was prosecuted by anti-vivisectionists. The charge against him fell unfounded.

If this brief notice has occupied itself chiefly with one outstanding achievement in the earlier career of a long and active life, that must not convey the impression that the subsequent years had not also their rich yield of labour given and worthy contributions made. It was as a lover of knowledge that Ferrier pursued knowledge. He had a share in many undertakings to foster and advance it. He was of those who at a meeting in London in the spring of 1876 founded the Physiological Society; the Society elected him to its honorary membership in January of last year. On the title-page of the Journal of Physiology his name has stood as a collaborator for thirty-four years continuously. $\mathrm{He}$ was one of the small band who in 1878 launched Brain. $\mathrm{He}$ was a founder of the Neurological Society in 1886 ; its president in 1894. His zeal and interest in neurology, and indeed other science, never staled. When he no longer himself carried on experimental research it afforded him pleasure to watch others experimenting. His talk possessed a certain penetrative piquancy partly veiled in simplicity ; it had a knack of getting to bottom. In literature he enjoyed dipping within the ancient classics. He was of artistic taste, in pictures as in other matters. The sea and the sea-coast were his favourite setting for a holiday. Numerous honours came to him. He was elected F.R.S. in 1876, and he received from the Royal Society a Royal medal in 1890. He was a laureate in Paris in 1878. His knighthood was conferred in 1911.

C. S. S.

\section{Miss J. E. HarRison.}

WE regret to record the death of Miss Jane Ellen Harrison, which took place in London on April 16, at the age of seventy-seven years. She was born in East Yorkshire on Sept. 9, 1850. At an early age she showed a special aptitude for languages, which she maintained until the end of her life. Before she entered Cheltenham Ladies' College at the age of fifteen, she had already acquired a knowledge of Latin, Greek, German, and Hebrew ; while after she had attained the age of seventy, she made herself acquainted with the elements of Persian.

Miss Harrison entered Newnham in 1874 and, it was stated privately, was at the head of the Second Class in the Classical Tripos in 1879. She returned to Newnham as a fellow in 1900 . On the termination of her college course she took up

$$
\text { No. 3053, VoL. 121] }
$$

